\title{
Maps and Charts
}

\section{Maps}

I. Distribution of Uniserial Harpoons and Wavy Line Pottery xxvi

2. Diffusion of Nostratic xxvii

3. Diffusion of Afroasiatic xxviii

3a. From Asia, Militarev and Schnirelman xxviii

3b. From Africa, Diakonoff xxix

3c. — Orel and Stolbova $\quad$ Xxx

3d. — Ehret

3e. $\longrightarrow$, Blench $\quad$ xxxii

3f. — Bender $\longrightarrow$ xxxiii

3g. —, Bernal, 1980 xxxiv

3h. — Bernal, $2004 \quad$ xxxv

4. Diffusion of Indo-European xxxvi

5. Ancient East Mediterranean xxxvii

6. Southern Greece xxxviii

7. Boiotia xxxviii

\section{Charts}

I. Indo-Hittite Language Family

xxxix 
xxvi

Maps and Charts

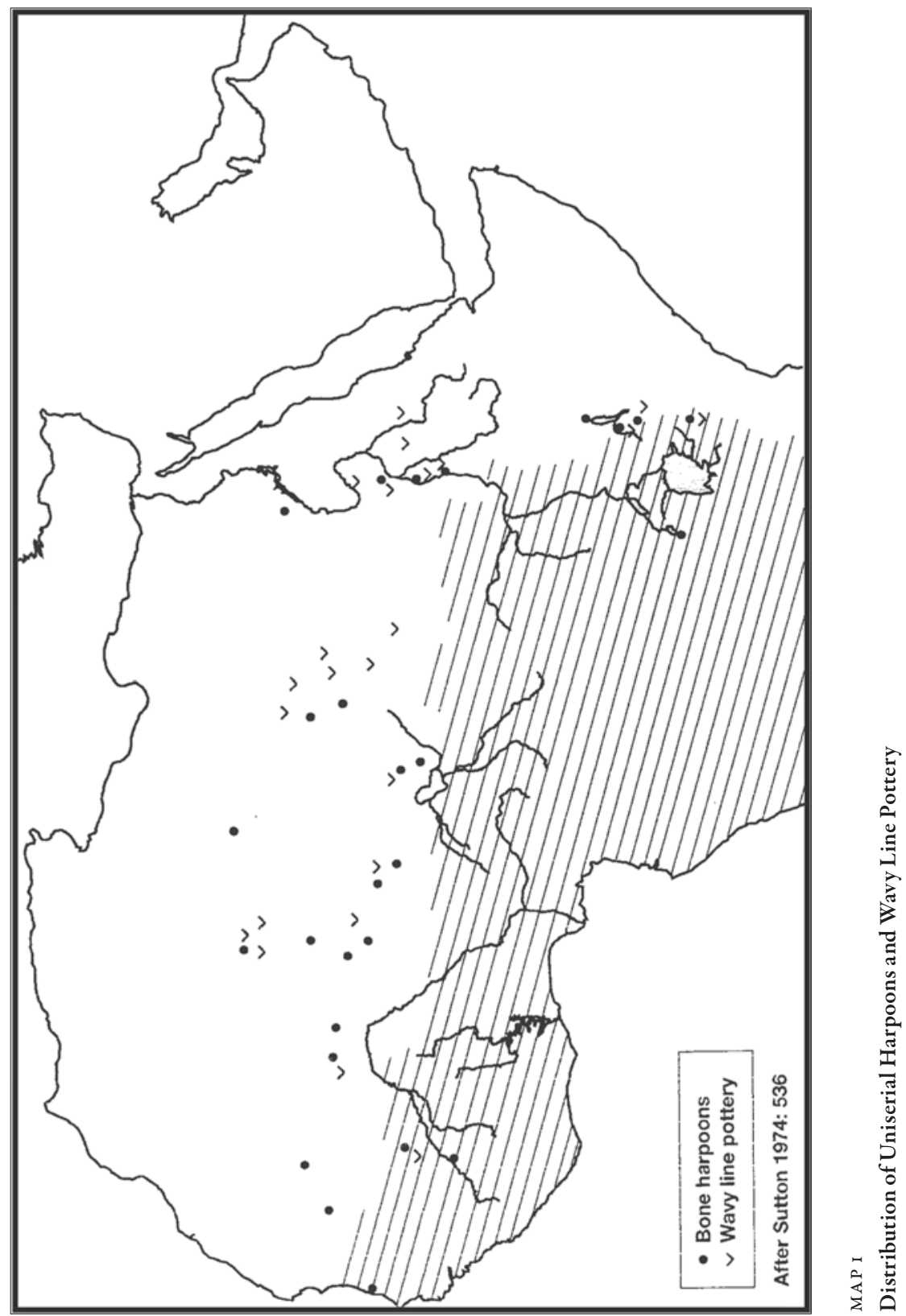




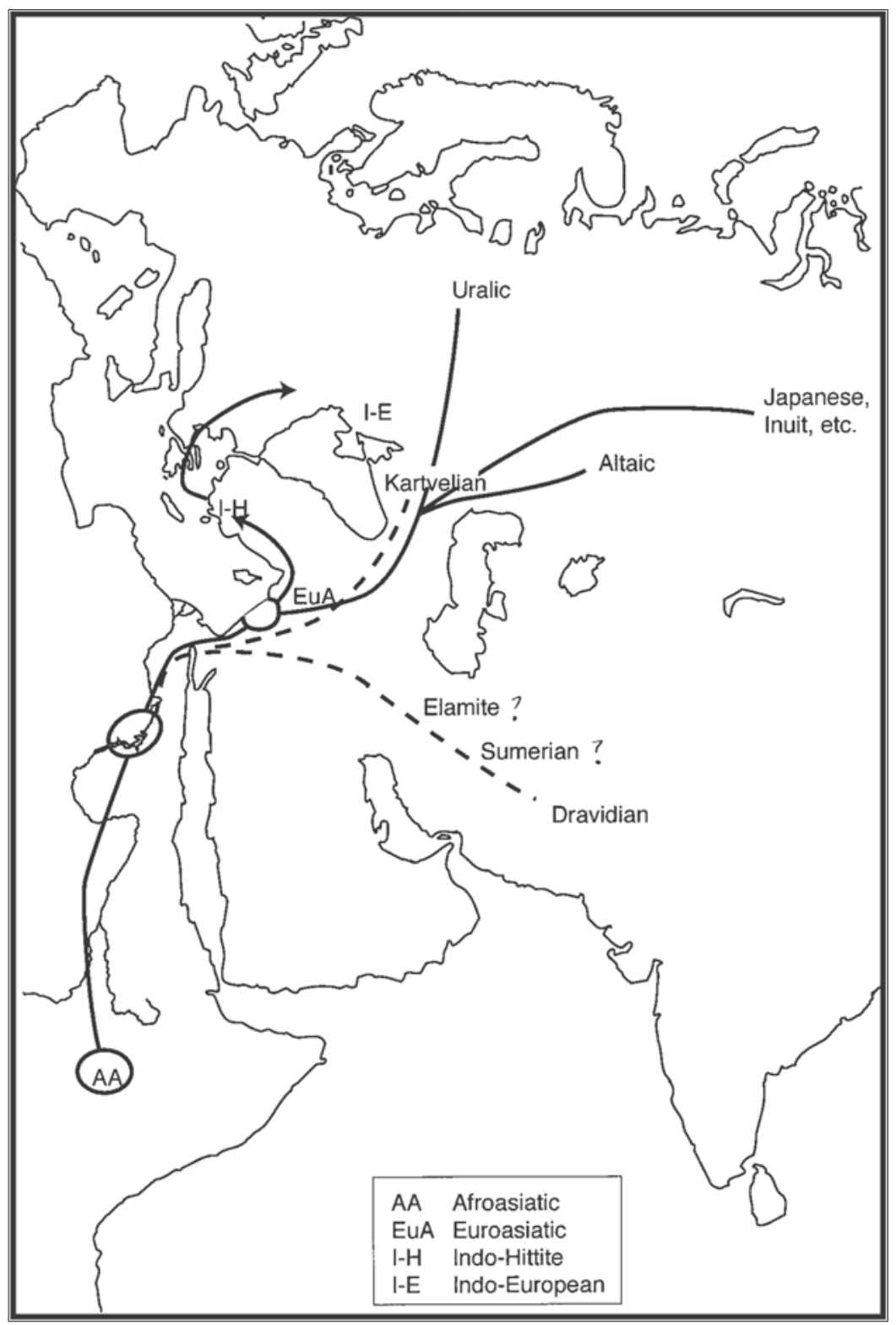

MAP 2

Diffusion of Nostratic 
xxviii

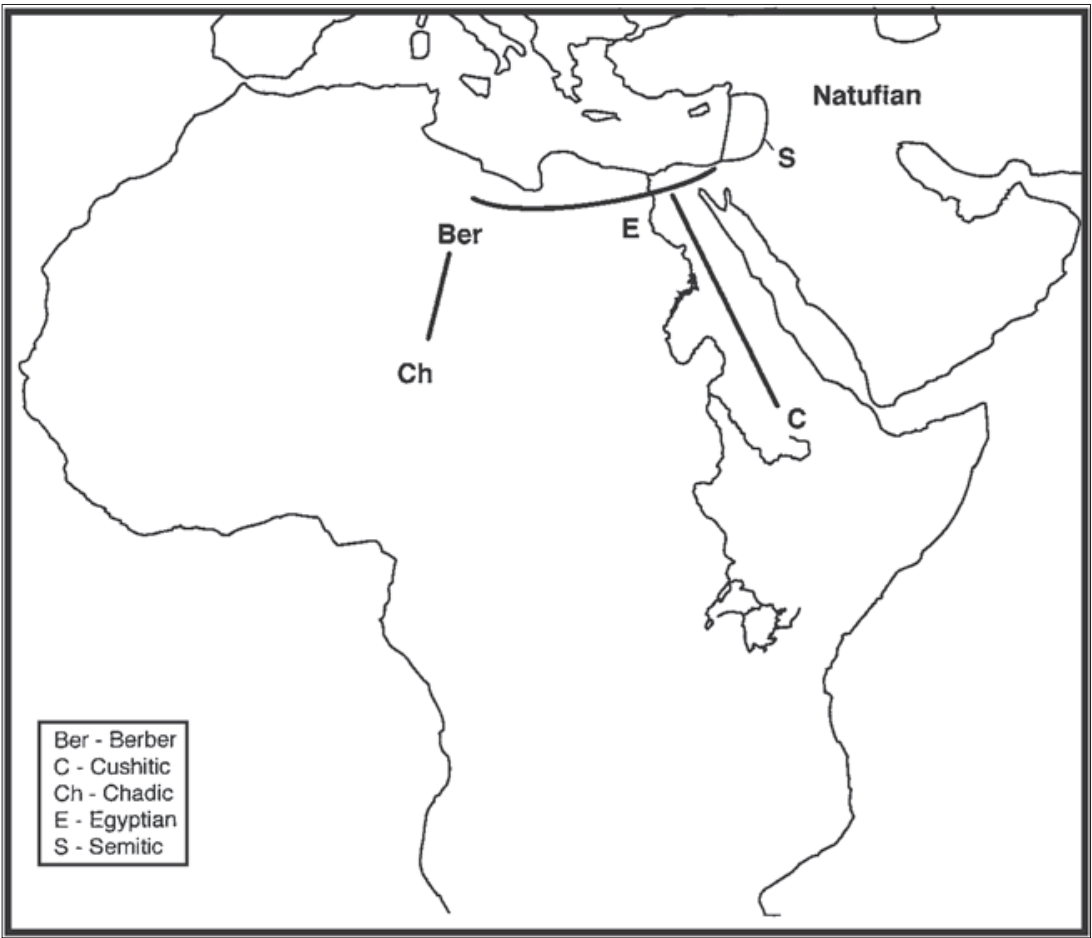

MAP $3 \mathrm{~A}$

Diffusion of Afroasiatic: From Asia, Militarev and Schnirelman 


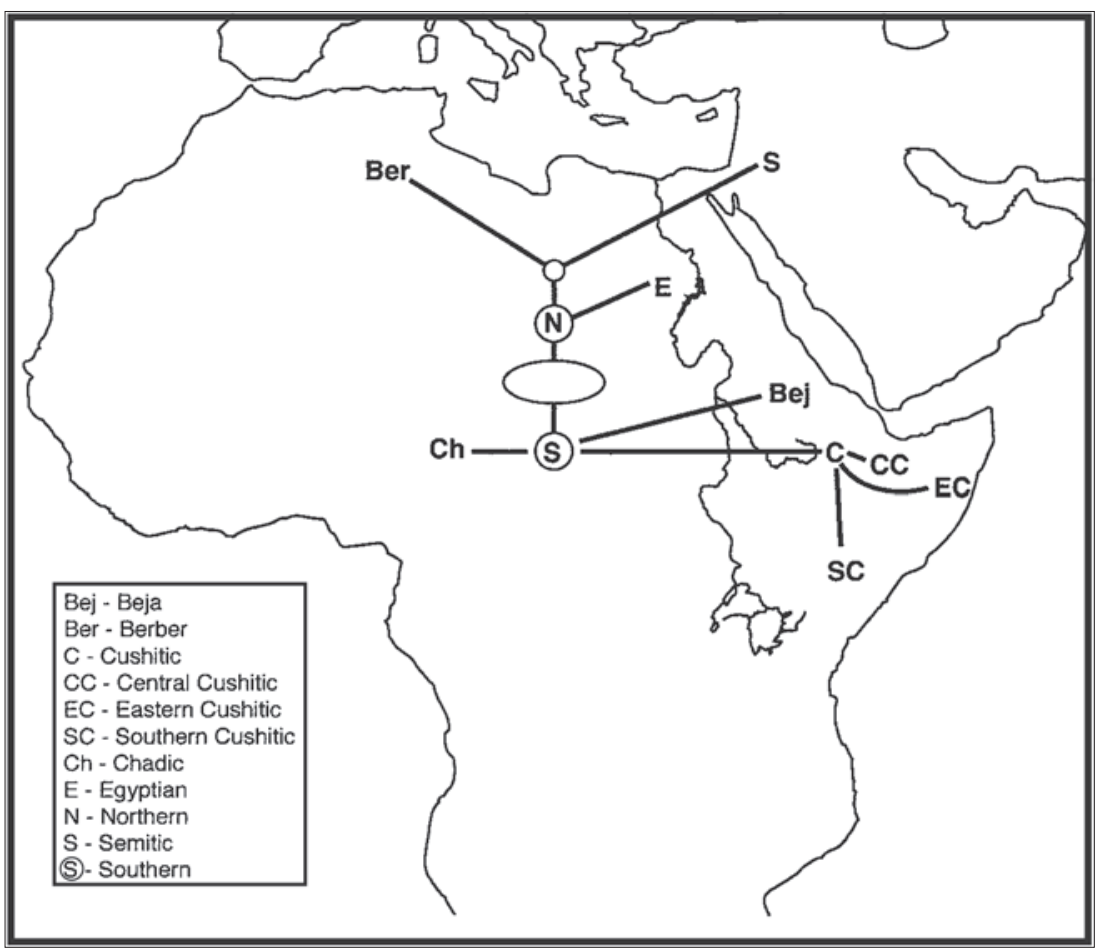

MAP $3 B$

Diffusion of Afroasiatic: From Africa, Diakonoff 


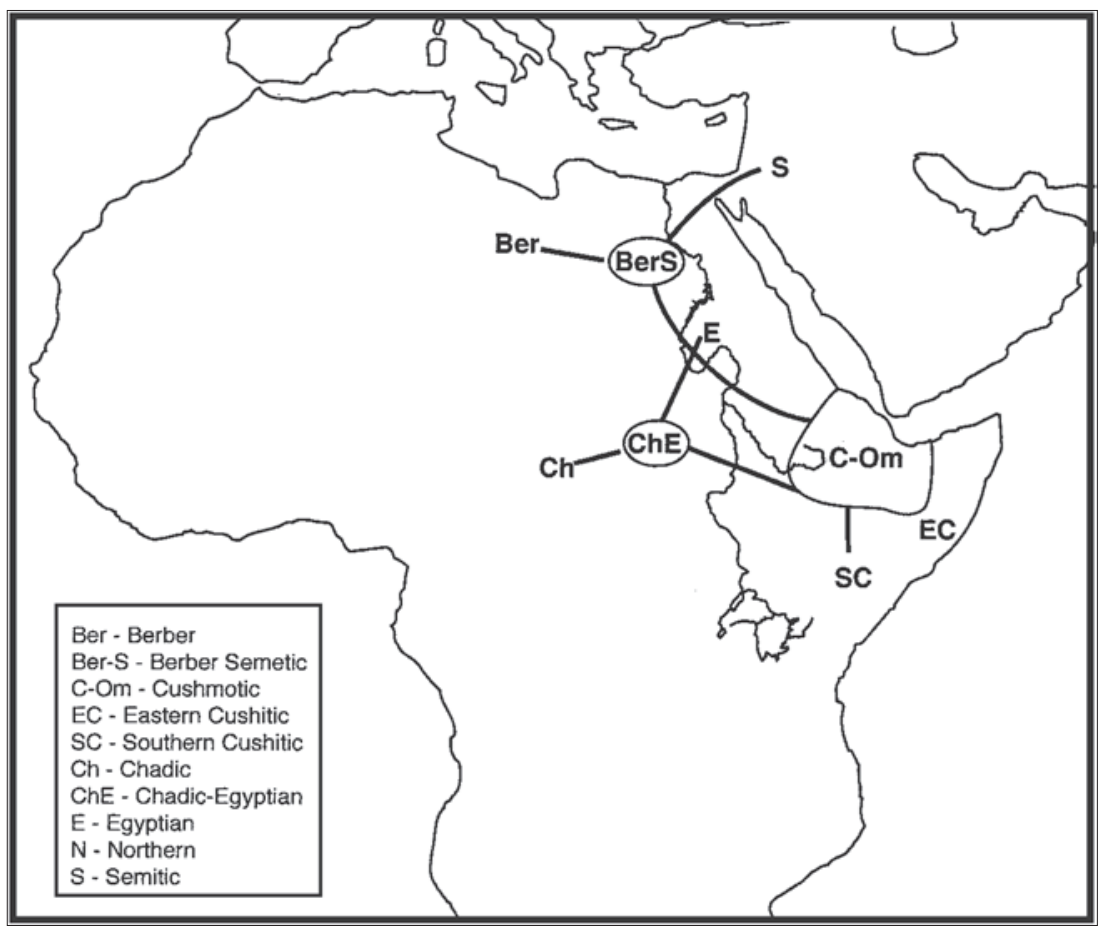

MAP 3C

Diffusion of Afroasiatic: From Africa, Orel and Stolbova 


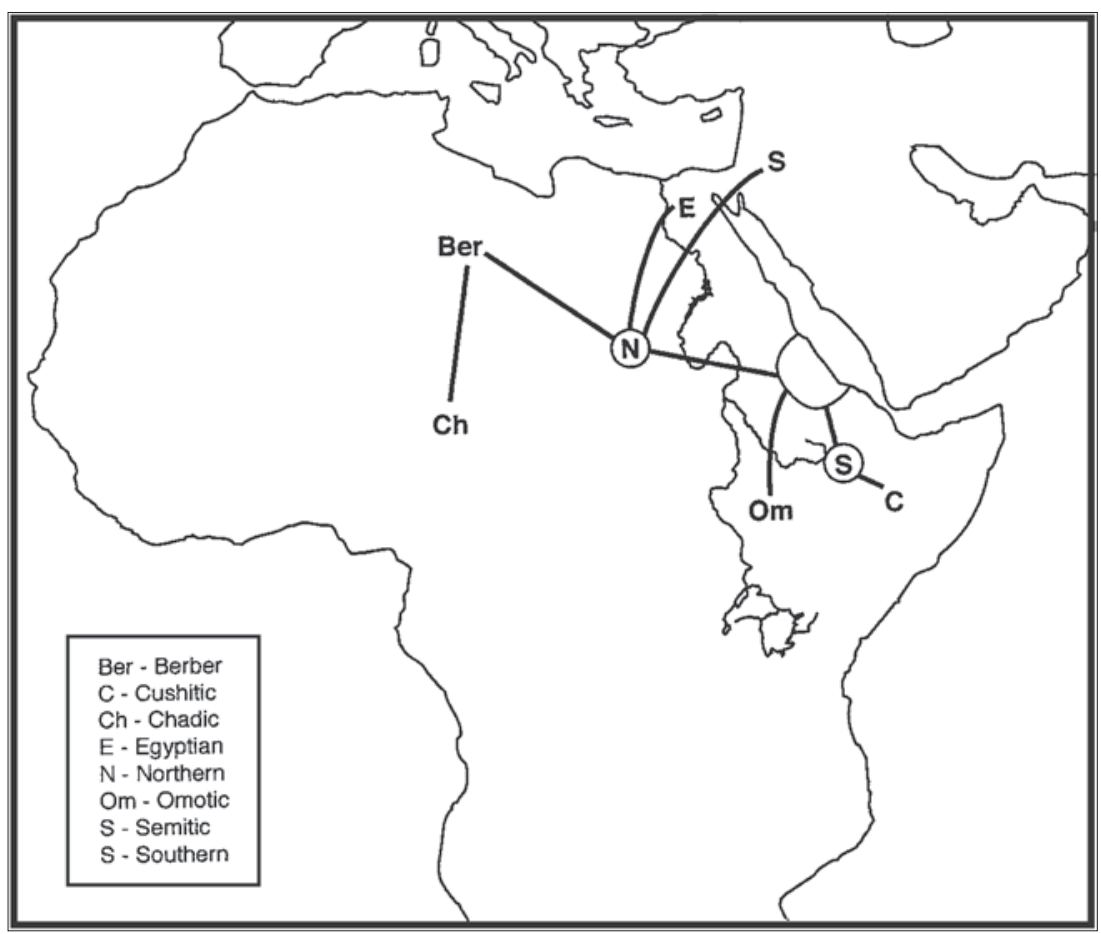

MAP 3D

Diffusion of Afroasiatic: From Africa, Ehret 


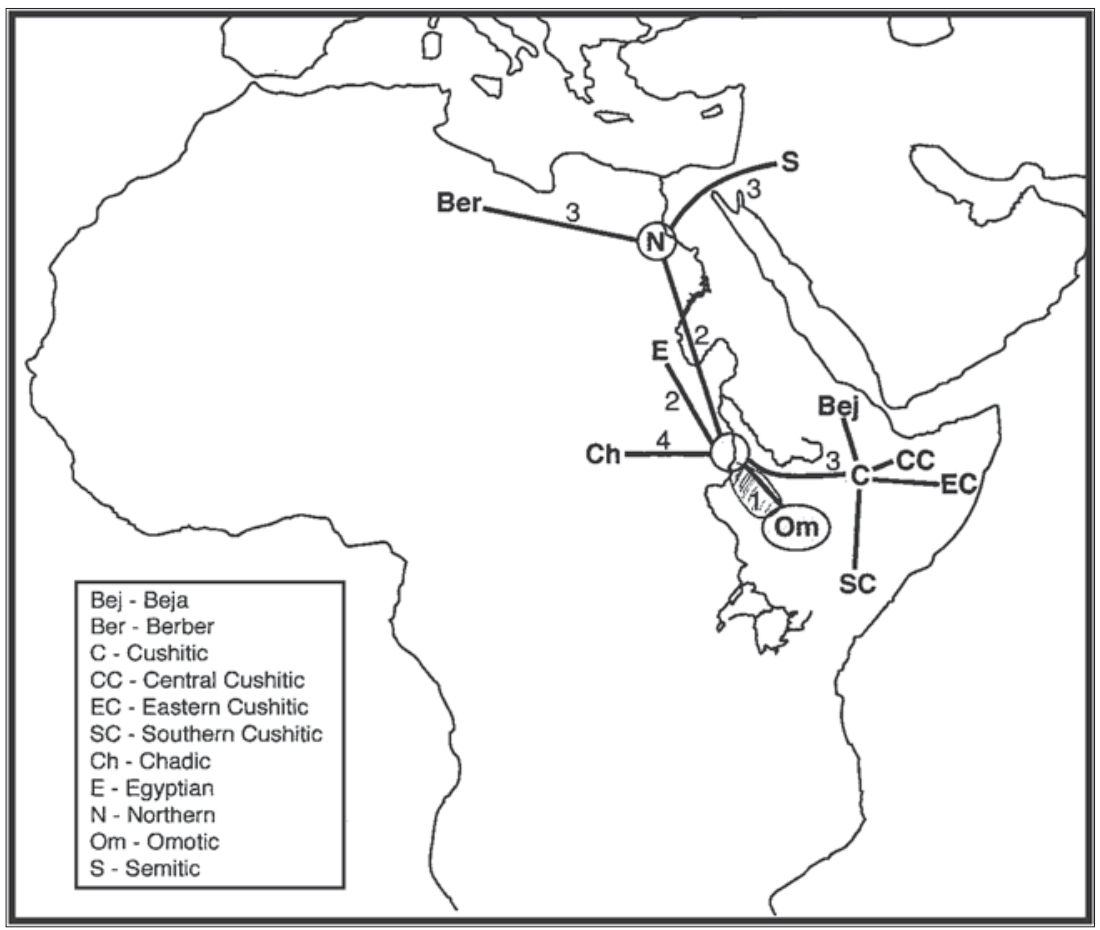

MAP 3 E

Diffusion of Afroasiatic: From Africa, Blench 


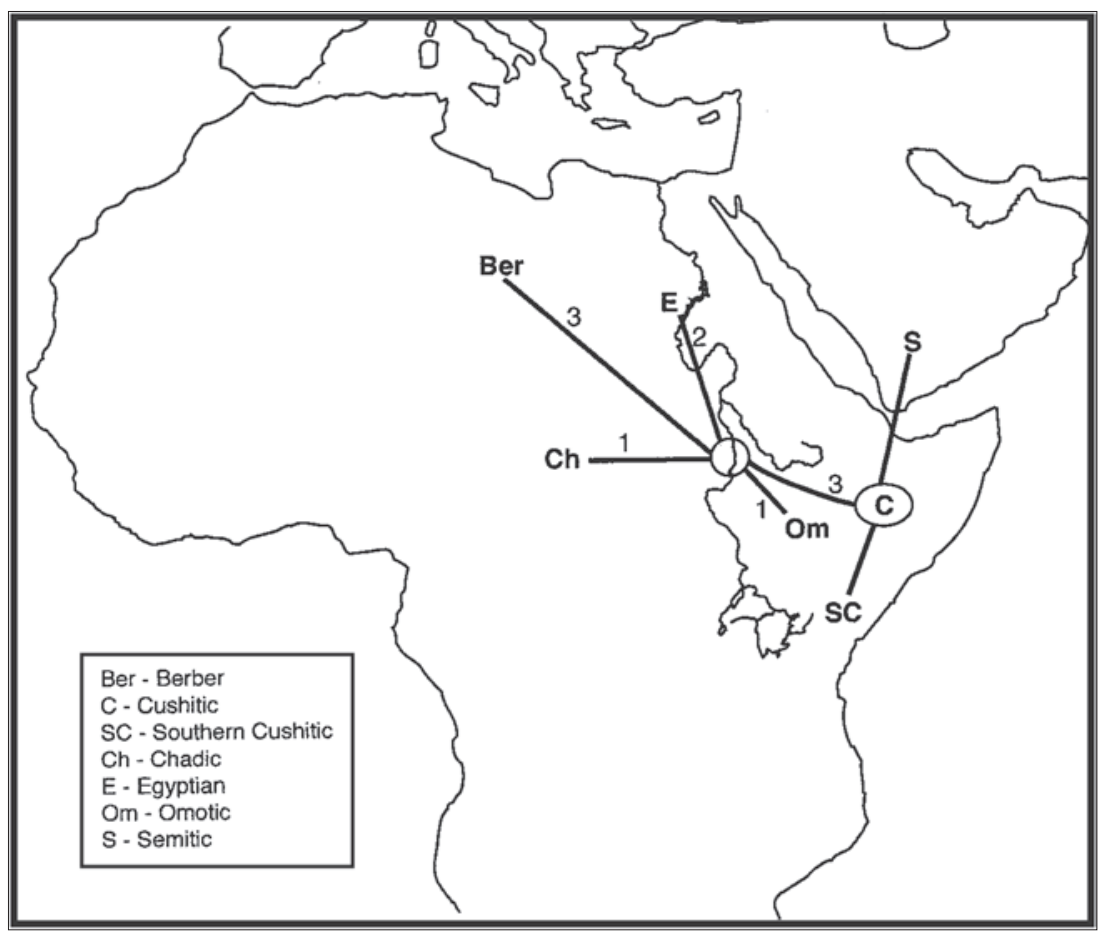

MAP $3 F$

Diffusion of Afroasiatic: From Africa, Bender 
xxxiv

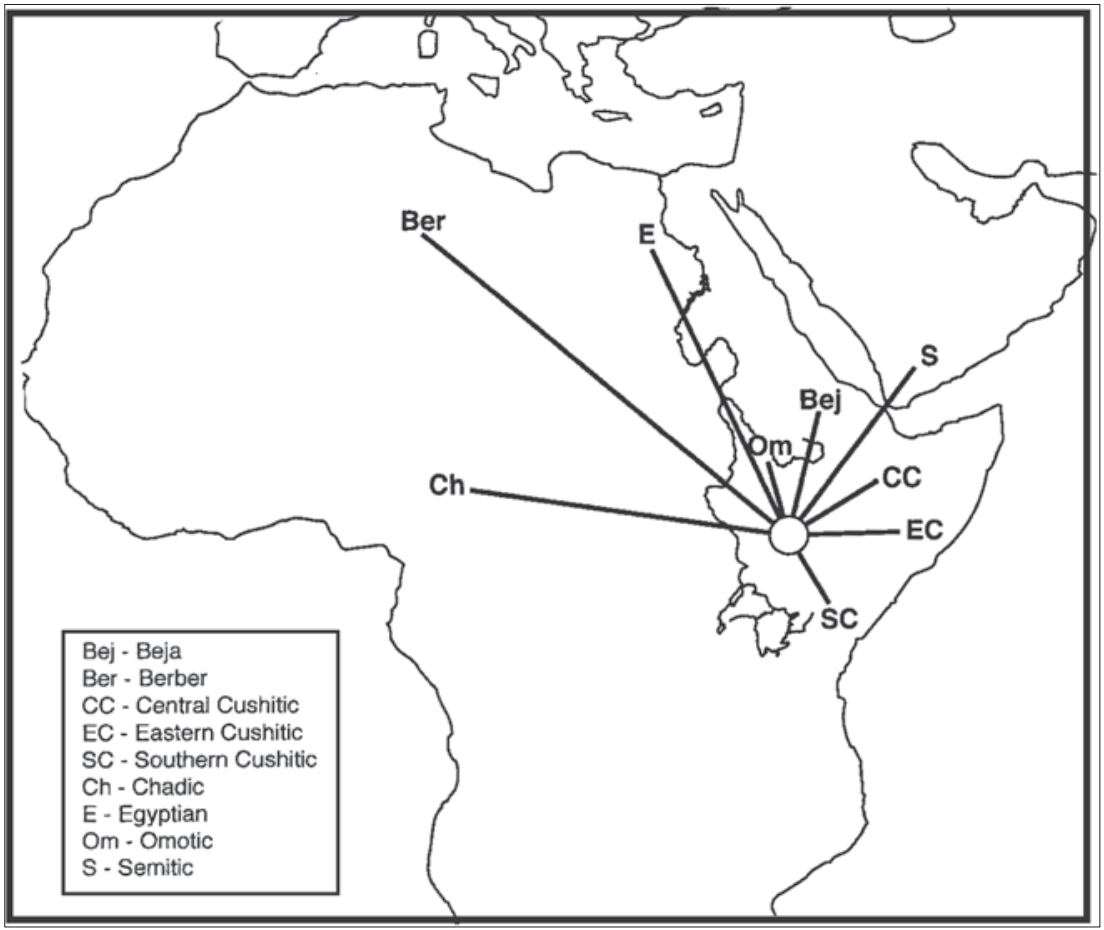

MAP 3G

Diffusion of Afroasiatic: From Africa, Bernal, 1980 


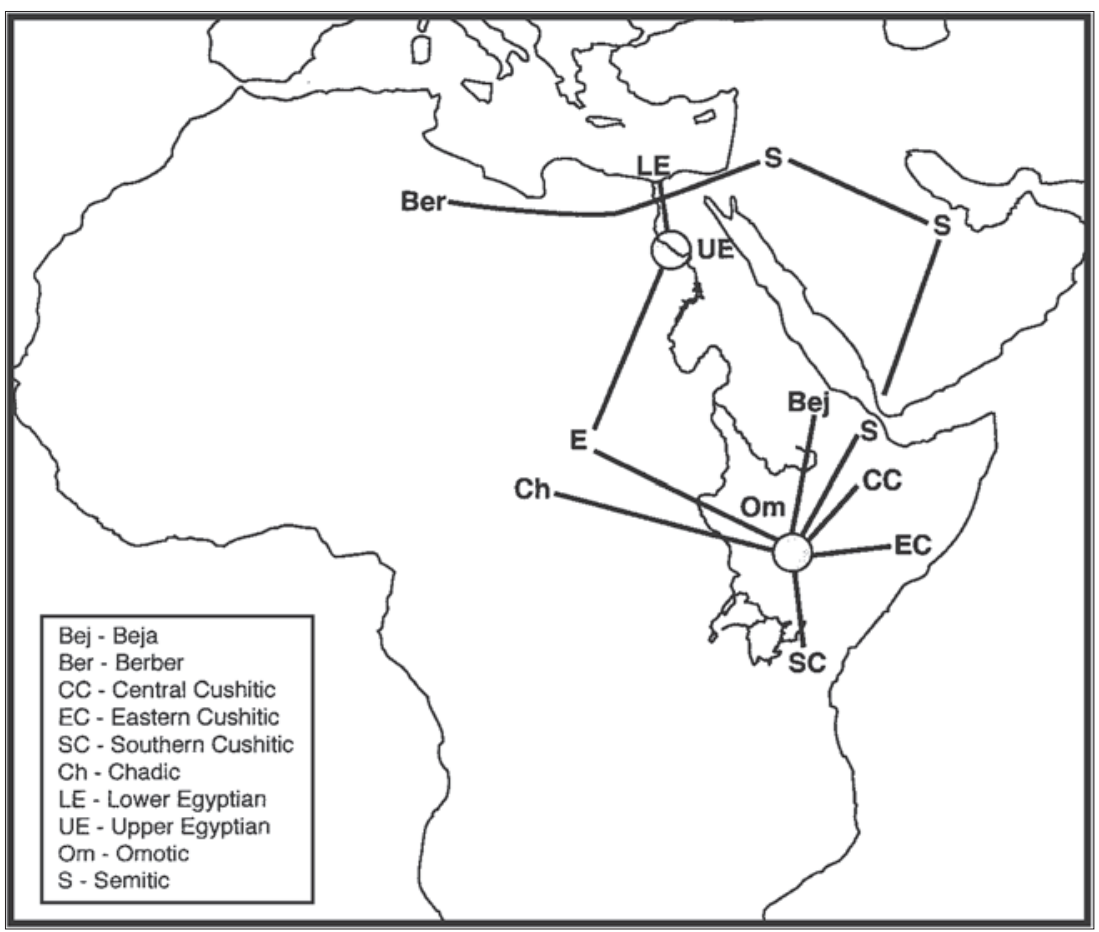

MAP $3 \mathrm{H}$

Diffusion of Afroasiatic: From Africa, Bernal, 2004 


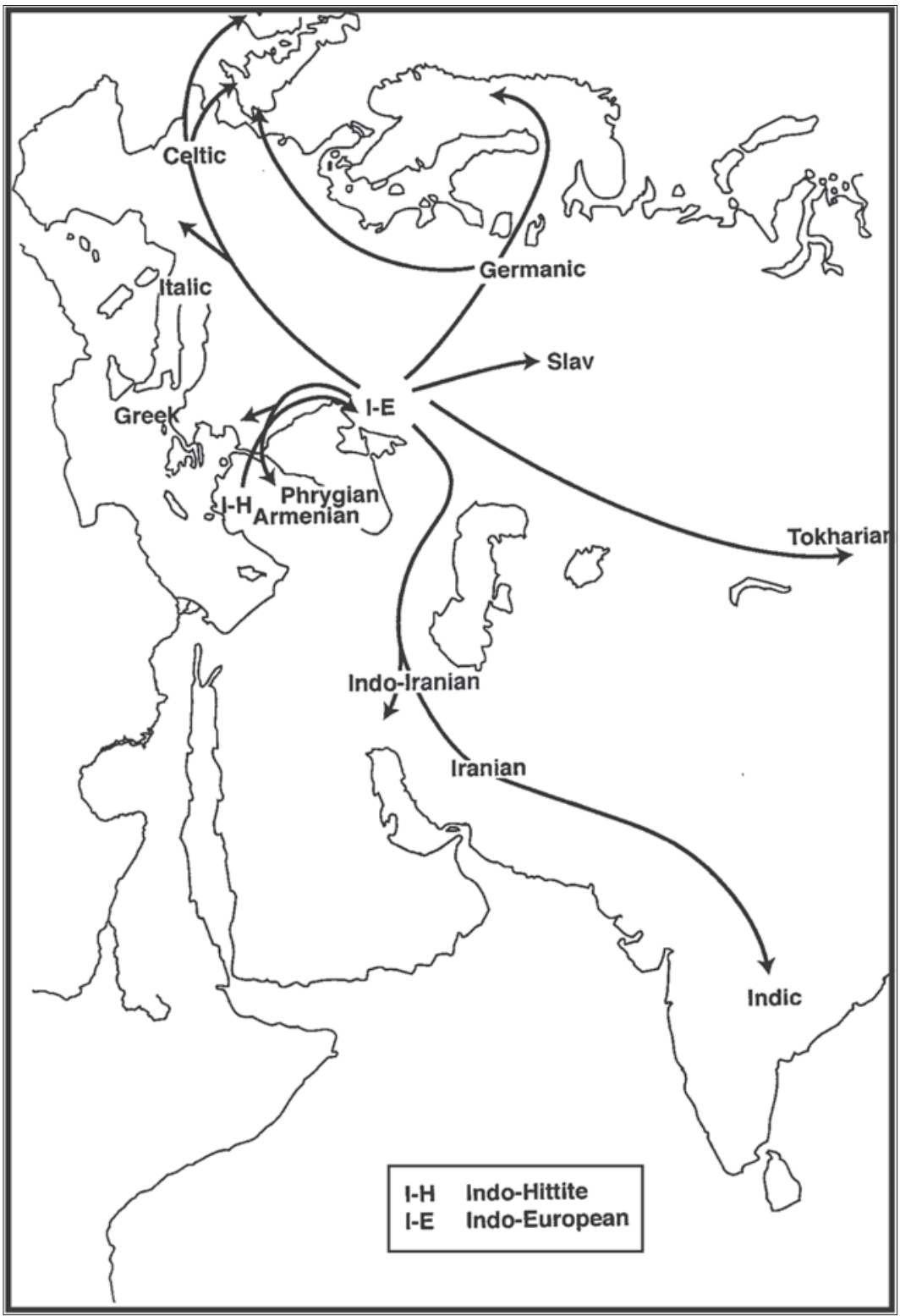

MAP 4

The Diffusion of Indo-European 


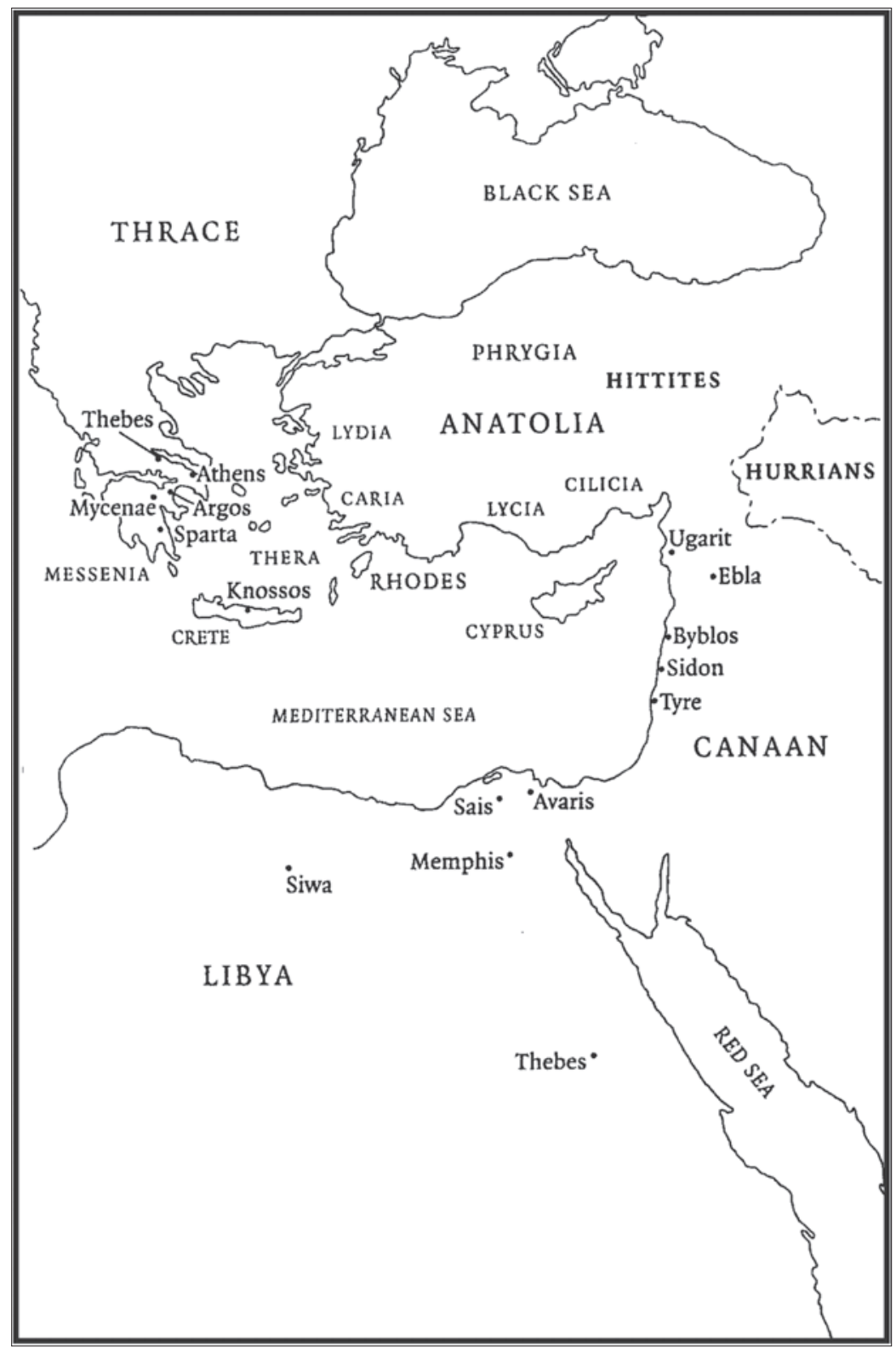

MAP 5

Ancient East Mediterranean 


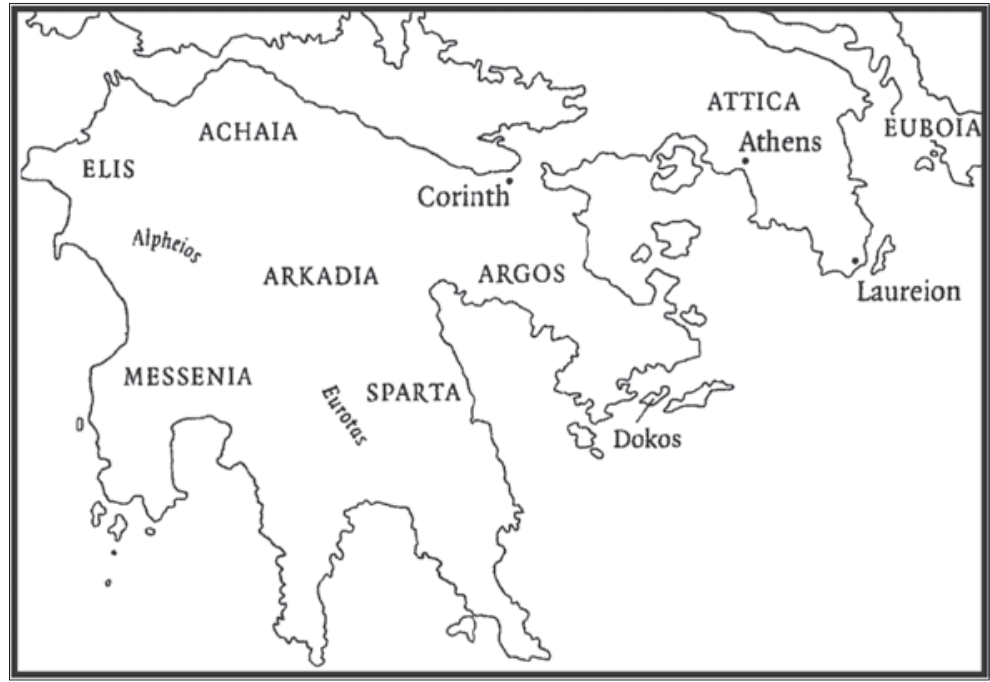

MAP 6

Southern Greece

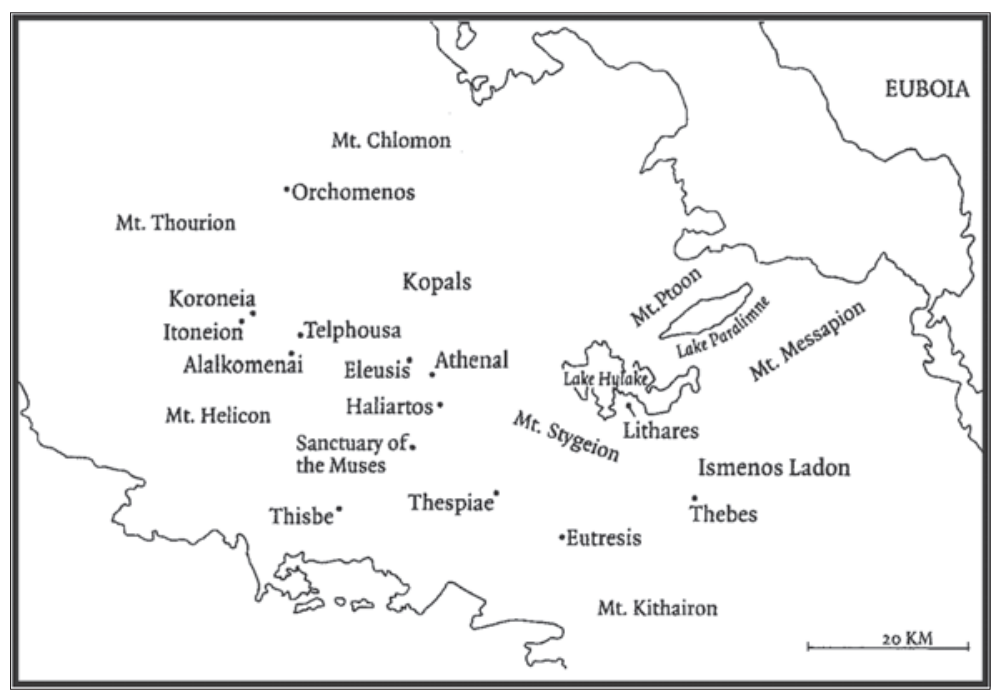

MAP 7

\section{Boiotia}




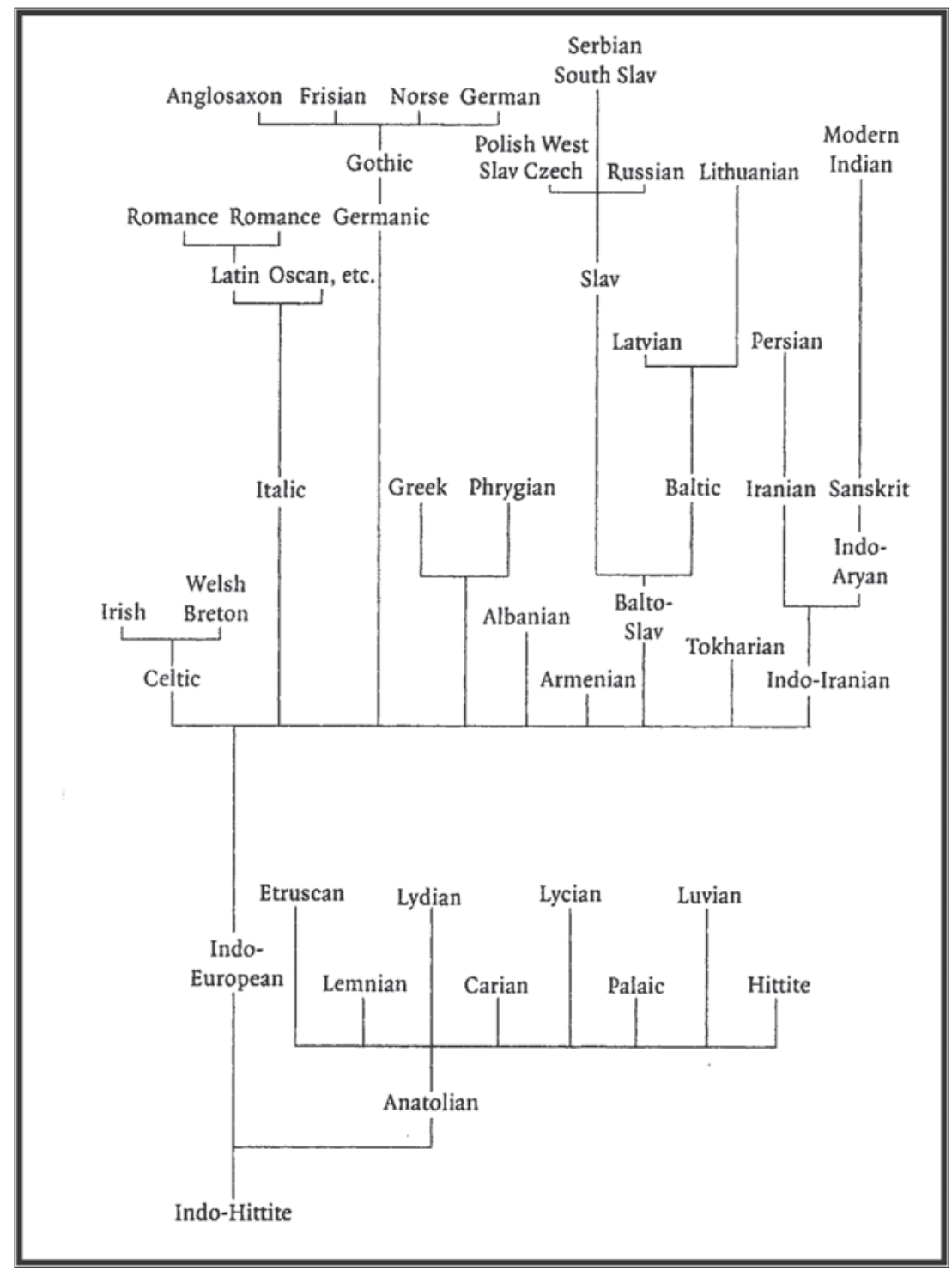

Chart I

Indo-Hittite Language Family 
